\title{
Quantifying the potential scale of mitigation deterrence from greenhouse gas removal techniques
}

\section{Duncan McLaren ${ }^{1}$ (DD}

Received: 4 April 2019 / Accepted: 27 April 2020 / Published online: 23 May 2020

(C) The Author(s) 2020

\begin{abstract}
Greenhouse gas removal (GGR) techniques appear to offer hopes of balancing limited global carbon budgets by removing substantial amounts of greenhouse gases from the atmosphere later this century. This hope rests on an assumption that GGR will largely supplement emissions reduction. The paper reviews the expectations of GGR implied by integrated assessment modelling, categorizes ways in which delivery or promises of GGR might instead deter or delay emissions reduction, and offers a preliminary estimate of the possible extent of three such forms of 'mitigation deterrence'. Type 1 is described as 'substitution and failure': an estimated 50-229 Gt-C (or 70\% of expected GGR) may substitute for emissions otherwise reduced, yet may not be delivered (as a result of political, economic or technical shortcomings, or subsequent leakage or diversion of captured carbon into short-term utilization). Type 2, described as 'rebounds', encompasses rebounds, multipliers, and side-effects, such as those arising from land-use change, or use of captured $\mathrm{CO}_{2}$ in enhanced oil recovery. A partial estimate suggests that this could add 25-134 Gt-C to unabated emissions. Type 3, described as 'imagined offsets', is estimated to affect $17-27 \%$ of the emissions reductions required, reducing abatement by a further 182-297 Gt-C. The combined effect of these unanticipated net additions of $\mathrm{CO}_{2}$ to the atmosphere is equivalent to an additional temperature rise of up to $1.4{ }^{\circ} \mathrm{C}$. The paper concludes that such a risk merits further deeper analysis and serious consideration of measures which might limit the occurrence and extent of mitigation deterrence.
\end{abstract}

Keywords Greenhouse gas removal $\cdot$ Mitigation deterrence $\cdot$ Climate policy $\cdot$ Climate modelling

Electronic supplementary material The online version of this article (https://doi.org/10.1007/s10584-02002732-3) contains supplementary material, which is available to authorized users.

Duncan McLaren

d.mclaren@lancaster.ac.uk

1 Lancaster Environment Centre, Lancaster University, Lancaster, UK 


\section{Introduction}

In the context of aspirations to limit the average global temperature rise, techniques which can draw greenhouse gases (GHG) from the air have become increasingly significant to climate policy. Integrated assessment models (IAMs) suggest that very substantial use of such techniques (variously termed carbon dioxide removal, negative emissions techniques, or greenhouse gas removal (GGR)) is likely necessary to stabilize atmospheric GHG concentrations at levels compatible with limiting average global temperature rises to $2{ }^{\circ} \mathrm{C}$ or lower (Fuss et al. 2014, Wiltshire and Davies-Barnard 2015, Minx et al. 2018). In modelled climate pathways that meet such goals, GGR is typically deployed later in the century (notably in the form of bioenergy with carbon capture and storage (BECCS)), alongside accelerated levels of other mitigation. In such pathways, GGR acts to balance carbon budgets in two ways: it promises to reverse an overshoot of emissions through future removals of $\mathrm{CO}_{2}$ from the atmosphere, and it offsets recalcitrant (difficult to eliminate) residual emissions. In policy terms, therefore, GGR is typically understood as an essential addition to otherwise constrained possibilities for effective and affordable mitigation. However, because IAMs typically seek to optimize costs, within such modelled pathways, some proportion of the anticipated GGR inevitably substitutes for otherwise expected emissions reductions, especially in the near-term (Azar et al. 2013, Riahi et al. 2015). In other words, late GGR typically replaces early mitigation.

It is therefore critical to better understand the interactions between GGR techniques and mitigation practices. In particular, might elevated consideration of GGR deter or delay otherwise anticipated emissions reductions? Might promises of GGR substitute for action to deliver or accelerate emissions cuts? In such cases, what happens if GGR fails to deliver on its promises? This is particularly important while GGR techniques remain largely technological imaginaries, unproven at the scale implied by modelling work. This paper seeks to categorize such interactions and the effects of such failures, and consider how significant they could be for the delivery of overall climate goals. Many researchers have questioned the technical feasibility of delivering the high levels of carbon removal implied in sub- $2{ }^{\circ} \mathrm{C}$ pathways modelling (Fuss et al. 2014, Anderson and Peters 2016, Larkin et al. 2017). Some have begun to explicitly estimate the additional risk to the climate should anticipated GGR fail to materialize (Realmonte et al. 2019). This paper combines such analysis with assessment of the extent to which promised GGR may substitute for emissions reductions rather than supplementing them. It also presents estimates of the potential scale of rebound effects or other indirect increases in emissions arising from the pursuit of GGR.

The paper first defines mitigation deterrence. It then discusses and begins to characterize possible mechanisms of mitigation deterrence within the modelling frameworks, and in relation to carbon budgets. It describes a 'carbon at risk' approach designed to enable assessment of the scale and significance of mitigation deterrence, and applies this to modelled estimates of GGR and emissions reduction to offer preliminary estimates of the possible impact. In doing so, it focuses on plausible worst-case scenarios, because of the irreversibility of decisions which substitute future GGR for earlier emissions reduction.

\section{Mitigation deterrence: definitions, mechanisms, and issues arising}

If mitigation is understood as planned at-source reductions in greenhouse gas emissions, then mitigation deterrence can be defined as the prospect of reduced or delayed at-source emissions 
reductions resulting from the introduction or consideration of another climate intervention (Markusson et al. 2018). Understood this way, mitigation deterrence will potentially, although not necessarily, increase climate risk. While climate interventions may also differ in their cobenefits or side-effects (Markusson et al. 2018), the focus here is on GGR as the 'other climate intervention', and on the potential that its introduction or consideration might (perversely) lead to a net increase in atmospheric GHG concentrations in comparison with a situation without such introduction or consideration. Interpreted in terms of carbon budgets, the concern is that the net result of the addition of GGR could be-rather than the achievement of a smaller residual emissions budget - a perverse increase in the scale and duration of any overshoot or exceedance of the budget.

This paper identifies three broad ways in which consideration or introduction of GGR could lead to unanticipated net additions to atmospheric GHGs over the coming century: first, if GGR formally substitutes for emissions reductions in plans and policies, and then fails to deliver removals matching the scale of the promised substitution (type 1 or 'substitution and failure'); second, if rebounds or other side effects from (attempted) GGR implementation generate emissions outside their anticipated budget (type 2 or 'rebounds'); and third, if the anticipated or 'imagined' future availability of GGR encourages or enables the avoidance or delay of emissions reductions without any planned or formal substitution mechanism (type 3 or 'mitigation foregone'). Together, the three types encompass both intentional and emergent responses to GGR consideration or deployment.

These three types or mechanisms of MD are briefly described and categorized below.

\subsection{Type 1: substitution and failure}

In type 1, failure implies that at a system level long-term removal of $\mathrm{CO}_{2}$ is not realized. That any given GGR technique itself may fail to capture $\mathrm{CO}_{2}$ from the atmosphere is only one of the diverse reasons why the complete socio-technical system may not deliver long-term removal. The largely unproven nature of GGR (Larkin et al. 2017; Rosen 2018) means that failures are clearly possible, but hard to quantify. Such failures might arise at various steps in the chain between atmosphere and storage (see Supplementary Fig. 1 for illustration). The technique might not prove commercially or technically viable, and thus not materialize, so failing to capture any carbon. Alternatively, it may prove less efficient (while still viable), with lower than anticipated rates of capture once full life-cycle carbon emissions are accounted for. In turn, this would imply higher unit costs and lower deployment rates. The overall efficiency of removal could also be depressed by carbon leakage from processing equipment, pipelines, or subsequent storage, or if carbon were diverted to utilization. Utilization as synthetic fuels, plastics, or building materials would only delay the return of $\mathrm{CO}_{2}$ to the atmosphere (by months, years, or perhaps decades). Leakage from storage may happen after some time, for example if a forest carbon store were to burn.

The maximum carbon directly at risk from failures in type 1 cannot, however, exceed the amount promised by successful deployment. Moreover, such failures only result in net increases in atmospheric GHGs (and thus additional climate change) insofar as GGRs have been permitted to substitute for emissions cuts or function as formal offsets for emissions growth. However, such effects can arise even if that substitution appeared 'rational' - costoptimal, for example - in foresight.

Substitution could come about in several ways. Actual or future GGR removals might be traded for emissions reductions in carbon markets. Policy makers could fail to increase targets 
for emissions reduction (which currently fall short of those required to deliver 1.5 or even $2{ }^{\circ} \mathrm{C}$ ), planning to make up the difference with GGR. GGR could be promoted as a substitute for feasible emissions cuts within a sector. For example, the agriculture sector might claim that soil carbon storage should be treated as an offset for remaining emissions from livestock that might otherwise be reduced by dietary change. GGR substitution could even be driven by an unrelated sector, such as by airlines developing voluntary offsetting schemes based on the purchase of GGRs.

Type 1 mitigation deterrence that adds to climate change is the result of both substitution and subsequent failure. To estimate its extent means quantifying not only how much carbon might be at risk of performance failure but also what proportion of this was an offset or substitute for planned mitigation actions. Type 1 mitigation deterrence constitutes budgeted emissions reductions that are substituted by GGR which fails to deliver. As a result, unabated emissions increase in comparison with the allowable carbon budget.

\subsection{Type 2: rebounds}

Unlike type 1, the carbon impacts of the remaining types of mitigation deterrence are not quantitatively limited by the scale of the carbon removal promised by GGRs. Type 2 constitutes rebounds and similar indirect and typically unintended effects in which GGR might trigger additional emissions. This could arise, for example, through use of captured carbon for enhanced oil recovery, from carbon emissions from soils converted to biomass production (or from associated indirect land use change), or from additional economic activity stimulated by any part of the GGR supply chain. With perverse incentives, or even just inaccurate data, a GGR developer might even continue to operate a technique which led to more emissions than it captured from the atmosphere. Such a problem could arise, for example, if a hypothetical GGR technology relying on gas as feedstock or energy source failed to account accurately for methane leakage in gas production (where estimates are disputed and differ by up to a factor of two (Alvarez et al. 2018)). Similar failings in the wider system (such as greater emissions from indirect land-use change (ILUC)) have been observed with biofuels, and therefore cannot be rejected here.

One notable risk amongst such unintended rebound effects of attempted material implementation of GGR would appear to be that of the injection of captured $\mathrm{CO}_{2}$ as a tool in enhanced oil recovery (EOR). EOR is already practised in most early BECCS schemes but could be used as a revenue source by any GGR producing compressed $\mathrm{CO}_{2}$ suitable for geological storage. Moreover, it is already incentivized by tax breaks in the USA (Bennett and Stanley 2018). There is typically more carbon in the additional oil recovered from EOR than stored (Godec et al. 2011, Armstrong and Styring 2015, Godec et al. 2017) and on average, EOR may even increase the GHG intensity of oil production (Masnadi and Brandt 2017).

All such rebound emissions are additional to the residual unabated emissions foreseen in the allowable carbon budget, and effectively increase baseline emissions. A comprehensive accounting of type 2 effects would require a detailed technical and economic analysis of the likely forms of GGR anticipated. Section 3.2 below gives an initial - and likely incompleteestimate focusing on land-use and EOR effects related to BECCS.

\subsection{Type 3: mitigation foregone}

Finally, in type 3 mitigation deterrence, the (immaterial) promise alone of GGRs may stimulate reductions in mitigation (or more likely, failures to increase mitigation) which exceed any 
apparently 'economically rational' substitution or planned formal offsetting - as included in type 1 above. This type more closely approximates fears of a classic 'moral hazard' effect in which merely considering an alternative triggers reduced effort to cut emissions (McLaren 2016). Type 3 is distinguished from type 1 because it represents mitigation foregone that is not matched even by any additional promises of GGR. It might help the reader to consider a simple example: assume that volunteers plant trees that are expected to capture $100 \mathrm{t}$ of carbon. That activity might be treated as a licence to continue emitting to that level, not only by the volunteers themselves but also by the organizers of the event, by the landowner, and also potentially by a purchaser of credits for the trees on a voluntary market. Only one of these 'offsets' is real (at best), the rest are imaginary. In reality, one might foresee even more complex situations where the potential removal is merely a promise or expectation, rather than an actual removal claimed multiple times.

Mitigation foregone through imagined offsetting leads to increased unabated emissions beyond those allowed within the carbon budget, regardless of whether the GGR that has been promised in modelled scenarios is delivered or not (Markusson et al. 2018). This is irrational at the system level, but not necessarily for individual actors, whose individual expectations that future GGR could replace each of their otherwise required emissions reductions might be reasonable, but in aggregate impractical. Many actors face political, financial, or cultural incentives to postpone mitigation in favour of future alternatives, with the promise of future GGR providing an ideal motivation to do so. Without some mechanism to restrain such imagined offsetting, it becomes plausible that the total mitigation deterred could exceed any possible practical future GGR capacity. It seems plausible that this effect is most likely where anticipated mitigation is - or appears to be - very costly. To make an initial estimate, this paper uses figures for the amount of mitigation anticipated to cost over $\$ 100$ per tonne of $\mathrm{CO}_{2}$, taking this threshold as representative of the 'promised cost' of large-scale carbon removal (Keith et al. 2018).

\subsection{Synergies and the 'plausible worst case'}

Given the diverse potential mechanisms included above, it is difficult to predict or quantify the possible scale and effects of mitigation deterrence. The counterfactuals are themselves riddled with uncertainties, and the innovation driving the evolution of this area is, by definition, unpredictable. Substitutions, failures, rebounds, and both formal and imagined offsets themselves can be expected to intersect and interact in diverse ways. It is conceivable also that there may be positive synergies that offset or even outweigh deterrence effects. For instance, the hope that carbon budgets can be balanced despite limited mitigation so far might galvanize action to cut emissions, or (somewhat contradictorily), awareness of the downsides of largescale GGR, such as pressure on food supply, might galvanize more rapid mitigation. Technical synergies might arise, for example if improved carbon capture technologies in direct air capture then cut the costs of fossil carbon capture and storage, enabling swifter emissions cuts. In the event of successful deployment of GGR, such synergies would result in greater reductions in GHG concentrations than anticipated in the modelled pathways.

This paper does not pursue the possibility of such positive synergies further. Unlike deterrence, some synergies are effectively already embedded in the learning curves applied by IAMs. Also, because of the potential risks involved, the focus here is on the possible negative interactions between GGR and mitigation. It should be incumbent on researchers and policy makers to consider the worst-case scenarios associated with the promises of new 
technologies such as GGRs. The remainder of this paper therefore focuses on an attempt to derive an initial estimate of the possible effect of mitigation deterrence should all the forms of deterrence identified here emerge in practice. To do this, it first explains how mitigation deterrence can be interpreted through carbon budget analysis.

\subsection{Mitigation deterrence and carbon budgets}

The approach builds on global cumulative carbon budget analysis (Anderson and Bows 2008, Allen et al. 2009) which identifies the cumulative emissions compatible with a particular chance of staying within a certain temperature. Despite various uncertainties (Peters et al. 2015, Rogelj et al. 2016, Millar et al. 2017, Peters 2018, Rogelj et al. 2018, Rogelj et al. 2019a), the IPCC (2018) suggests a range of $115-210 \mathrm{Gt}-\mathrm{C}$ remaining for $1.5^{\circ} \mathrm{C}$ as of 2017 . Given current emissions rates, by 2020 this implies just $80-176$ Gt-C remaining (in the Supplementary material, this is termed $\mathrm{CBUD}_{1.5}$ ).

Figure 1 illustrates the three types of mitigation deterrence and how they relate to carbon budgets. It shows comparative cumulative global carbon budgets to 2100 in three climate policy states. The first column depicts a carbon budget prior to consideration of GGRs. For the sake of illustration, imagine that this budget is commensurate with restricting temperature rise to $2{ }^{\circ} \mathrm{C}$. The total bar represents the aggregate carbon emissions anticipated between 2020 and 2100 in the absence of any intervention. The lower pale grey section represents the emissions reduction required to avoid dangerous climate change, leaving an allowance of cumulative residual unabated emissions - the 'permitted budget' for $2{ }^{\circ} \mathrm{C}$ - (shown in the upper dark grey section). The dark and pale grey sections are schematically proportionately scaled to reflect mainstream estimates of the remaining permitted carbon budget and the overall cuts in emissions implied.

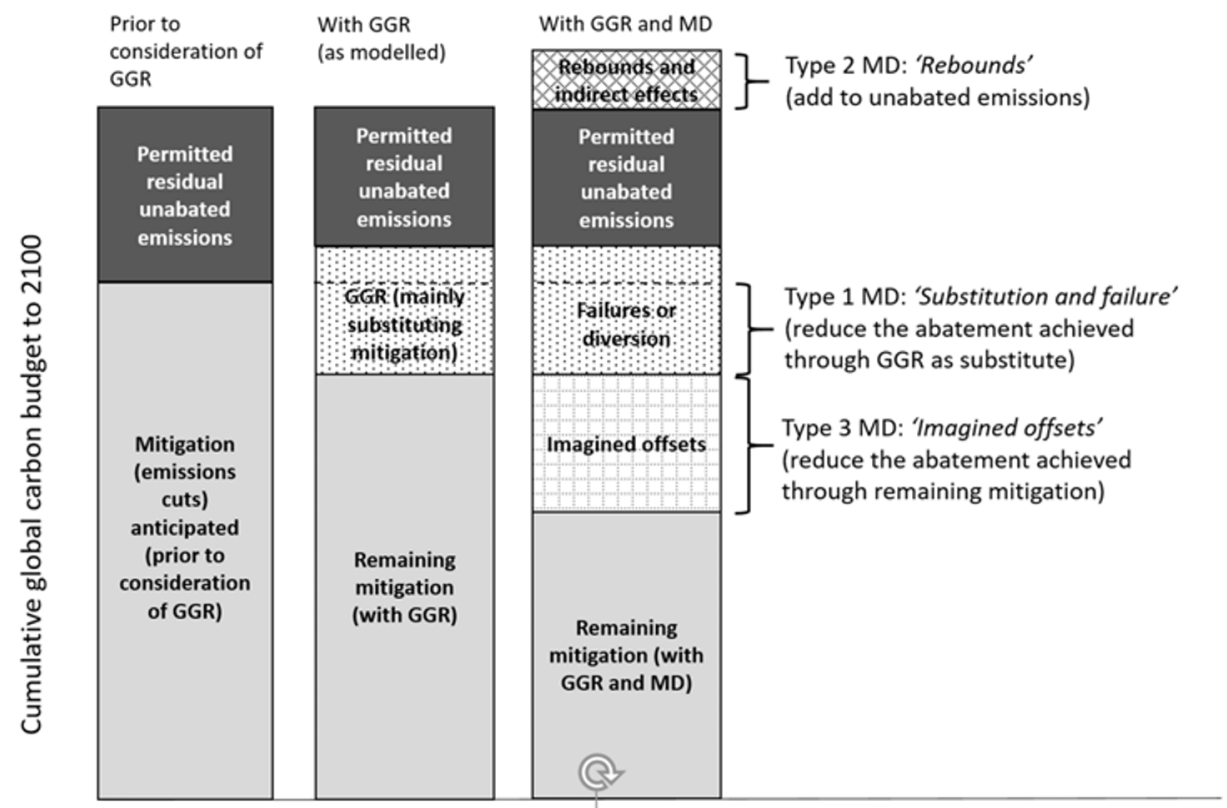

Fig. 1 Schematic representation of putative global carbon budgets to 2100 under three different climate management scenarios including mitigation deterrence (see text for full explanation) 
The residual budget for a $1.5{ }^{\circ} \mathrm{C}$ target would be smaller than that for a $2{ }^{\circ} \mathrm{C}$ target, constituting perhaps just $10-15 \%$ of the otherwise anticipated cumulative emissions to 2100 (80-176 Gt-C of otherwise anticipated emissions, under RCP 4.5 or RCP 6.0, of around 650$1300 \mathrm{Gt}-\mathrm{C})$. In an effort to meet this reduced budget and deliver the tighter temperature target, policy makers might turn to GGR. Alternatively, GGR (shown as the dotted central portion in column 2) might be seen as a way to respond to delays in mitigation, or to increase the likelihood of meeting the temperature goal: all three of these goals effectively shrink the remaining residual emissions allowance. The second column represents the ways models portray the introduction of GGR. In practice, they interpret the 'promises' of GGRs, as partly contributing to, and partly increasing the mitigation expected (represented by the dashed line dividing the GGR portion of the column). Previous modelling suggests a substantial degree of substitution (represented by the dotted area below the dashed line), as apparently affordable later GGR replaces more expensive early mitigation (Azar et al. 2013; Riahi et al. 2015). The precise location of the boundary between GGR removals that supplement emissions reduction and those that substitute for it is debateable (and depends partly on the modelling techniques applied). The proportionate scale of the GGR contribution shown here is roughly indicative of the amounts suggested in the literature.

The central argument in this paper is that the picture provided by column two is misleading, as it ignores a series of plausible dynamic responses to the introduction of GGR promises. These are represented in the third column. Firstly, all of the GGR contribution (dotted area) would be at risk if GGRs were to fail completely (with the part of the dotted area below the dashed line representing type 1 mitigation deterrence as described above). In addition, there may be substantial risks from the two further distinctive types of mitigation deterrence noted above (shown here as cross-hatched areas). Again, the relative scale of the sections schematically reflects the numbers in the analysis below, but here the uncertainties are much greater. The diagonally crosshatched area (type 2) represents additional unabated emissions from rebounds and other side effects of GGRs, and thus increases overall emissions (raising the height of the column). Like type 1, it can be estimated as a function of the promised or attempted deployment of GGR, and the risk grows the more GGR is anticipated. On the other hand, the horizontally crosshatched area (type 3) represents mitigation foregone in the hope of GGR, and thus increases the residual unabated emissions by reducing anticipated mitigation (shown as a reduction in the pale grey portion of the column). As can be seen in column three, the more GGR substitutes for mitigation in type 1, the smaller the remaining volume of mitigation anticipated becomes, and thus there is less anticipated mitigation for type 3 to affect (and vice versa). The relationship between the quantity of GGR anticipated and type 3 deterrence is therefore an inverse one.

'Recalcitrant' (or hard to eliminate) emissions up to 2100 are included in the dark grey blocks in this schematic, although their extent is a matter of contention. GGR as a tool to offset recalcitrant emissions forms a part of the dotted area above the dashed line. Failure of such GGR is not considered mitigation deterrence, as it has not substituted for emissions reductions. However, given uncertainties over which emissions are genuinely recalcitrant, especially over multi-decadal timescales, one must also note that GGR promises could enable a growth in spurious 'recalcitrant emissions' (if, for example, new near zero carbon technologies for steel and cement production (Material Economics 2019) are resisted to prolong the life of existing industrial assets).

It must also be noted that any continuing 'recalcitrant' emissions beyond 2100 would need to be offset by continuing GGR deployment, in addition to any GGR needed to recover 
overshoot emissions accrued by 2100. Such deployment of GGR beyond 2100 is not considered further here. Nor are the implications of there being potentially 'stranded' GGR assets once any overshoot has been dealt with, even though this might create political and financial incentives to permit continued emissions.

This paper uses estimates derived from modelling work, despite the shortcomings of IAMs, for three reasons. First, such models provide figures within a consistent framework, enabling the derivation of a preliminary estimate. Second, this approach should make the estimates more accessible to the policy communities that make use of existing modelling results as an input for their deliberations. The promises embedded in modelling are here treated as indicative of current expectations amongst the climate policy community. While the outcomes of integrated assessment modelling do not determine the intentions and actions of climate policy, the expectations and technology choices that modelling embodies would appear to both reflect and influence policy makers' aspirations nationally and internationally (Beck and Mahony 2018). Third, by relating the estimates made here to the outcomes of IAMs, the paper can indicate ways in which such models - or their interpretation - might be improved to take more account of the risks of mitigation deterrence.

The next section outlines quantitative estimates of the amount of carbon at risk from mitigation deterrence.

\section{Carbon at risk}

This section aims to quantify the carbon at risk from mitigation deterrence, taking each of the three types of deterrence set out above in turn. Throughout, figures are presented in terms of carbon equivalents ((giga)tonnes of carbon), and in cumulative amounts from 2020 to 2100 except where otherwise specified. A detailed account of the methodology can be found in the Supplementary material and Supplementary Table 1.

\subsection{Carbon at risk from 'substitution and failure': type 1 mitigation deterrence}

This section presents a preliminary cumulative estimate of 50-229 Gt-C of expected GGR that substitutes for mitigation and may be vulnerable to failure $\left(\mathrm{MD}_{1}\right.$ in the Supplementary material).

Table 1 Summary calculations of carbon 'at risk' from mitigation deterrence (Gt-C)

\begin{tabular}{llll}
\hline & $\begin{array}{l}\text { Low } \\
\text { estimate }\end{array}$ & $\begin{array}{l}\text { Central } \\
\text { estimate }\end{array}$ & $\begin{array}{l}\text { High } \\
\text { estimate }\end{array}$ \\
\hline $\begin{array}{l}\text { Carbon at risk from GGR substitution and failure (type 1) } \\
\text { Carbon at risk from rebounds \& other side-effects (type 2) }\end{array}$ & 50 & 156 & 229 \\
$\begin{array}{l}\text { Carbon at risk from mitigation foregone in imagined offsetting } \\
\quad \text { Type 3) }\end{array}$ & 297 & 71 & 134 \\
Total carbon at risk & 371 & 444 & 52 \\
\hline
\end{tabular}

The low estimate for type 1 is based on IPPC figures alone, the high estimate also relies on Realmonte et al. 2019 (see methodology), the central estimate is a median of the two approaches. All the estimates of type 3 reflect only an RCP6.0 counterfactual and assume that in scenarios with high promised GGR, there will be less residual expensive mitigation at risk from type 3 , and vice versa) 
There are a wide range of claims and estimates about the potential for different types of carbon removal. This section relies primarily on the summary of the range of GGR deployment required in the IPCC special report on $1.5{ }^{\circ} \mathrm{C}$, both as a way to simplify a complex field and to focus on the way in which modelled expectations influence policy makers.

In no- and low-overshoot scenarios achieving $1.5^{\circ} \mathrm{C}$, the special report suggests a range of cumulative GGR to 2100 of 71-281 Gt-C (IPCC 2018). This may be conservative in several respects: it excludes high-overshoot scenarios which return to $1.5{ }^{\circ} \mathrm{C}$ after exceeding $1.8^{\circ} \mathrm{C}$; it reflects a larger permitted budget than previous analysis (based on Millar et al. (2017)); and it is based largely on modelling using Shared SocioEconomic Pathways (SSPs), which imply significant inbuilt decarbonization from historically unprecedented high-efficiency uptake, and low growth rates. Furthermore, because studies targeting $1.5^{\circ} \mathrm{C}$ tend to present figures only for favourable contexts in which the models can still resolve for $1.5{ }^{\circ} \mathrm{C}$, their GGR figures may actually be underestimates compared with the amounts that may be deployed in practice in an effort to restrain temperature rises. These factors may also help us understand why the IPPC's 2018 GGR requirement for $1.5{ }^{\circ} \mathrm{C}$ is lower than the $362 \mathrm{Gt}-\mathrm{C}$ calculated by Wiltshire and Davies-Barnard (2015) for all IPCC pathways with a $90 \%$ chance of avoiding $2{ }^{\circ} \mathrm{C}$ (and similar to the same authors' figure for the median of all $2{ }^{\circ} \mathrm{C}$ pathways (166Gt-C)).

Moreover, almost all modelling to date has deployed BECCS as the only cost-effective technological GGR option. As a measure of the level of GGR mobilized in the models to meet particular carbon budgets and particular temperature outcomes, BECCS has therefore functioned as a placeholder for all GGR, even though it has been increasingly constrained in models because of concerns that the levels modelled might not prove practical. However, the IPCC synthesis figure based on such studies is significantly lower than the 164-327 Gt-C contribution of GGR modelled by Realmonte et al. (2019) in the only intermodel study to incorporate both BECCS and DAC technologies. The analysis in the paper therefore also uses this higher range (described as GGR $_{\mathrm{dac}}$ in the Supplementary material) in calculations of the upper bound of type 1 deterrence (see Supplementary Table 2, and Table 1 below), recognizing that in the real world, promises of future DAC circulate alongside promises of future BECCS.

The technical feasibility of the delivery of hundreds of gigatonnes of GGR has already been questioned, in particular given the prevalence in the models of BECCS (Wiltshire and Davies-Barnard 2015; Anderson and Peters 2016; Vaughan and Gough 2016; Rosen 2018). Such critiques have stressed competition for land, and the prospect of countervailing increases in emissions from direct and indirect land-use change. However, such analysis has not previously been brought together with an assessment of the extent to which GGR substitutes for mitigation within the modelled pathways, rather than supplementing it (as done here).

\subsubsection{Why substitution matters, and how much it happens in models}

If the carbon projected to be captured and stored in GGR were all additional to anticipated emissions reductions, then underperformance would merely reduce the additional abatement achieved relative to the baseline scenario. As undesirable as that prospect might be, GGR would still be contributing, albeit in a limited way, to the abatement of climate 
change. But if the projected GGR substitutes partly or wholly for carbon that would otherwise have been abated through emissions reductions, then the net effect of reliance on underperforming GGRs could be a perverse and unexpected net increase in GHG concentrations relative to the baseline. In other words, if there is both substitution and failure, there is deterrence which increases climate risk.

Here, a figure of $70 \%$ is applied to illustrate a plausible rate of substitution. This is a central figure derived from two different approaches, as detailed in the Supplementary material. First, the GGR requirements modelled in recent work exploring extremely ambitious mitigation (Grubler et al. 2018, van Vuuren et al. 2018 are compared with the median GGR requirement in SR1.5. Second, a figure is calculated from previous studies that quantify the decrement in emissions reduction arising from the introduction of GGR in the same model (Azar et al. 2013, Riahi et al. 2015).

On the basis of $70 \%$ substitution, if no GGR materializes, then - as a first approximation, as a result of type 1 mitigation deterrence - in the order of 50-197 Gt-C more carbon will accumulate in the atmosphere over the period to 2100 than anticipated by the IPCC ( $70 \%$ of the IPCCC range of 71-281 Gt-C). At the same ratio, the higher GGR requirement modelled by Realmonte et al. would translate to a range of carbon at risk of 115$229 \mathrm{Gt}-\mathrm{C}$. On the other hand, in low GGR scenarios, one might wish to assume that less of the remaining GGR is a substitute, and more of it deals with genuinely recalcitrant emissions (and vice versa in high GGR scenarios). In this case, applying the lower and upper figures calculated from Grubler et al. (35\%, and 84\%, as shown in Supplementary Material), the type 1 range extends to $25-235 \mathrm{Gt}-\mathrm{C}$. In what follows, a low figure of $50 \mathrm{Gt}-$ $\mathrm{C}$ (from the IPCC-based calculation) and a high figure of $229 \mathrm{Gt}-\mathrm{C}$ based on the more recent Realmonte et al. study (2019) are used.

Scenarios of continued substitution and complete failure may seem unlikely, as they imply a period of 70-80 years in which GGR remains a technical promise, but delivers no practical results. However, decades of unfulfilled promises of fusion power should give us pause for thought, as should recent experience with CCS (Markusson et al. 2017). Moreover, some modellers are already extending the timelines for overshoot into the twenty-second century, in which case it becomes easier to postulate that unredeemed promises might continue to wield legitimacy even as this century comes to an end.

GGRs substitute for emissions reduction in IAMs as a result of cost optimization (and discounting) (Bednar et al. 2019). In comparison with a $2{ }^{\circ} \mathrm{C}$ target, a $1.5{ }^{\circ} \mathrm{C}$ target tends to increase the contribution of GGR to the overall carbon budget by a greater relative amount, but a smaller absolute amount, than the increased contribution of emissions reductions (Rogelj et al. (2018), Luderer et al. (2018)). In cost-optimizing models, the absolute level of such substitution might be expected to grow with higher carbon prices resulting from smaller available carbon budgets. But it cannot be taken for granted that such high carbon prices will emerge in practice, nor that they would actually deliver high GGR deployment. Substitution might be reduced in modelling by preventing even temporary exceedances of the outcome temperature goal, which in turn would prevent the models from using late GGR to recover from a temperature overshoot driven by delayed emissions reduction (Rogelj et al. 2019b). This could reduce the risk of type $1 \mathrm{MD}$, but might imply earlier GGR deployment, possibly thereby exacerbating type 2 risks, and would likely reduce overall expected GGR deployment, thus increasing the scope of type 3 risks. 


\section{Box: An example of mitigation substitution from the EU}

Recent research shows how the introduction of GGR to the policy mix could affect emissions reductions at a more detailed scale (Rodriguez et al. 2017). Conventional pathways for the EU towards its 2050 target of an $80 \%$ reduction in emissions over 1990 levels (an absolute target of around $0.6 \mathrm{Gt}-\mathrm{CO}_{2} \mathrm{pa}$ ) involve virtual decarbonisation of electricity generation (-97.5\%), combined with aggressive policies to reduce emissions in other sectors. The introduction of BECCS transforms the picture. The target is then achieved with the help of around $0.8 \mathrm{Gt}-\mathrm{CO}_{2}$ pa BECCS removals. Emissions in the electricity sector fall by $152 \%$ over 1990 levels. But cost effective reductions in other sectors become much smaller. Emissions reductions in industry are only $65 \%$ in the presence of BECCS, rather than $78 \%$ without. In buildings the emissions cuts shrink from $87 \%$ to $36 \%$. And in transport, emissions reductions are decimated, falling from $61 \%$ to just $10 \%$. The mitigation 'foregone' in these three sectors as a result of the introduction of BECCS adds to almost $0.7 \mathrm{Gt}-\mathrm{CO} 2$ pa. This is equivalent to almost $25 \%$ of the otherwise expected mitigation, and almost $90 \%$ of the carbon removed by BECCS simply substitutes for emissions reduction.

For transport emissions to be cut by $61 \%$ would imply substantial investments in hydrogen (or electric) vehicles, requiring transformation of a major industrial sector. In the buildings sector, the different paths might imply very different standards for new buildings, very different replacement rates, and very different rates and standards of refurbishment. Retrospectively implementing such paths after a delay of decades waiting for BECCS to prove its viability would be largely impractical.

\subsection{Carbon at risk from rebounds, multipliers, and side effects: type $\mathbf{2}$ mitigation deterrence}

The carbon at risk from type 2 mitigation deterrence (rebounds, multipliers, and side effects) is more difficult to calculate. It cannot be derived simply from an analysis of modelled outcomes. The initial estimates here indicate a cumulative range of $25-134 \mathrm{Gt}-\mathrm{C}\left(\mathrm{MD}_{2}\right.$ in the Supplementary material) based on combining conservative estimates of diversion to enhanced oil recovery, and indirect land use change.

An estimate of 25-79 Gt-C from enhanced oil recovery (EOR) is suggested here. EOR can act as a multiplier of atmospheric carbon. Godec et al. (2011) estimate a global potential for incremental production by EOR of 470-1070 billion barrels of oil. For each barrel, $82 \mathrm{~kg}-\mathrm{C}$ (300 kg-CO ${ }_{2}$ ) would be stored (Godec et al), and 117-155 kg-C emitted (see Supplementary material), with the higher figure accounting for additional upstream emissions and co-products. However, in low GGR scenarios, there may not be enough compressed $\mathrm{CO}_{2}$ produced to meet even the low potential for EOR storage, especially if there is no BECCS deployed, and this would reduce the carbon at risk below $25 \mathrm{Gt}-\mathrm{C}$. On the other hand, if EOR potential exceeds the estimates cited here, then more of the anticipated carbon capture in BECCS and DAC might be diverted to EOR. In high-GGR scenarios, the supply of compressed $\mathrm{CO}_{2}$ could be 34 times greater than the maximum amount directed to EOR here, potentially increasing the rebound proportionately.

Attribution of emissions from land-use change (LUC) resulting from bioenergy has proved difficult and contentious. Estimates of indirect land-use change (ILUC) factors for net carbon emissions range from as little as $5 \%$ to over $100 \%$ globally (with a central range of 10-20\% even for well-managed bioenergy systems) (Souza et al. 2013). On the basis of a 10-20\% emissions rebound from land use change associated with the bioenergy component of BECCS, a BECCS deployment of 0-273 Gt-C (IPCC 2018), might generate 0-55 Gt-C of additional emissions. However, with elevated demands for land in comparison with bioenergy so far, it is possible that that BECCS-driven LUC could lead to higher additional indirect emissions, especially if land brought into new production held significant carbon reservoirs (e.g. old growth forest, deep prairie soils, or peat swamps). 
These rebound effects are not limited to BECCS and could result from other GGR techniques also. Biochar, soil carbon storage, and enhanced weathering all have land-use implications. DAC carbon could also be diverted to EOR. However, EOR and ILUC effects could easily both arise in a BECCS-based GGR economy. BECCS would both support conversion of land to biomass production (with implications for ILUC) and generate compressed $\mathrm{CO}_{2}$ requiring storage, which could be diverted to enhanced oil recovery. Commercial incentives to minimize the marginal costs of BECCS would drive both effects as developers seek to cut costs in the biomass supply chain, and obtain a return on the $\mathrm{CO}_{2}$ stored. Similarly, careful design of interventions and incentives might help reduce either effect.

Our combined estimate of type 2 effects (25-134 Gt-C) makes no allowance for any possible Keynesian multiplier based on increased purchasing power resulting from public spending on GGR. However, it should be noted that decision makers investing in GGR would likely aim to maximize any such multiplier effects, because the economic co-benefits of green jobs, skill development, and exports that can come alongside the development of new green technology are politically desirable. Such multipliers may be particularly significant where the techniques involved might spin off new technological breakthroughs. Such multipliers are distinct from classic economic rebound effects, where efficiency of use makes a resource relatively cheaper. If carbon removal leads to lower carbon prices than otherwise, there will be some classic rebound effects. This, however, is already embodied in the substitution effect in type 1 mitigation.

\subsection{Carbon at risk from 'mitigation foregone' in 'imagined offsets': type 3 mitigation deterrence}

The third form of deterrence is also hard to quantify. Here, an estimate of $182-297 \mathrm{Gt}-\mathrm{C}\left(\mathrm{MD}_{3}\right.$ in the Supplementary material) is presented.

As noted in section 3.1, IAMs with assumed rational agents imply significant costoptimizing substitution of future GGR for near-term mitigation. Type 3 concerns instead ways in which real-world responses to the promise of GGR might exceed the 'economically rational' substitution generated in IAMs. This is not to concede that it is indeed rational to replace nearterm mitigation with carbon drawdown based on technological imaginaries, but rather to note that there are other mechanisms (not captured by the models) that could stimulate apparently irrational behaviours, and to assess their likely impacts on overall abatement. The term 'imagined offsets' is used to describe a situation in which an actor foregoes mitigation because they imagine that the emissions involved will be offset by other actions elsewhere or in the future. In this way, promises of GGR could add to existing excuses for delay and inaction, while their inter-temporal nature would appear to make them more pernicious in this respect than promises relating to more conventional mitigation technologies.

Imagined offsets are distinct from formal offsets, such as those generated in carbon markets, even though the latter might also fail to deliver in practice, as a result of double counting or leakage (see section 3.1). Imagined offsetting arises where near-term actors behave as though future GGR will be less costly than current mitigation, and thus continue to emit, effectively assuming that their emissions will be offset by unspecified future removals. But collectively, their expectations of GGR exceed possible deployment rates, limited by resource constraints or sustainability factors. At the system level, it would be irrational for all such actors to defer mitigation, but at the individual level, each such action might appear reasonable. In practice, such actors may well face private costs per tonne of mitigation that are higher than the estimated social 
costs which drive policy. Moreover, such actors may apply higher discount rates to their individual actions than the model applies at a system level (where the discount rate typically reflects anticipated climate damages rather than contemporary time preferences) (Jouini et al. 2010, Goulder and Williams 2012). Both these factors raise the possibility of imagined offsetting by making future GGR appear relatively cheap in comparison with near-term mitigation, and thus making a greater share of modelled mitigation vulnerable to deterrence.

Such deterrence could arise even without any deliberate intent to undermine or delay progress on mitigation, motivated by political or economic interests. Well-meaning promises of GGR could, for example, depress carbon prices in trading markets, affecting many decision makers unknowingly. But in the presence of vested interests, which deliberately act to make near-term mitigation appear more costly and undesirable than it is portrayed in the models (Oreskes and Conway 2011), then there is an additional reason to anticipate that promises of GGR might be mobilized to defer mitigation action. This echoes ways previous promises of CCS have been deployed (Markusson et al. 2017). Markusson et al.'s analysis of CCS further implies that the more GGR might impose a real economic cost on dominant political or economic actors, the less likely it would be to rapidly materialize in practice, and the more likely it would be to be pushed further into the future.

Estimates of the amount of mitigation forecast to cost more than $\$ 100 / t-\mathrm{CO}_{2}$ are used here to derive a proxy for imaginary offsetting. Advocates often suggest that GGR might cost significantly less than $\$ 100$ (McLaren 2012, Wilcox et al. 2017, Fuss et al. 2018, Keith et al. 2018), so this appears a plausible level to consider. In practice, such costs for GGR may only prove possible in specific, limited, applications which might not deliver substantial levels of long-term removal (such as BECCS on ethanol, enhanced weathering using slags, or DAC to produce dilute $\mathrm{CO}_{2}$ ). However, the impression of low costs tends to circulate more widely and misleadingly adhere to other-more expensive - formulations of the techniques, exacerbating the risk of type 3 effects.

Under an RCP6.0 baseline, 50\% of mitigation (or a median of 543Gt-C) would cost above the $\$ 100 / \mathrm{t}-\mathrm{CO}_{2}$ threshold (IPCC 2007) (see Supplementary material and Supplementary Table 1 for calculations) However, of this amount, 80-176 Gt-C is the remaining permitted unabated cumulative emission, and (assuming that GGR substitutes only for more expensive mitigation) a further 71-281 Gt-C would be removed by GGR. This leaves a residual of expensive mitigation required of $182-297 \mathrm{Gt}-\mathrm{C}$ to achieve a $1.5^{\circ} \mathrm{C}$ outcome. This amount (or $17-27 \%$ of all mitigation) is considered to be at risk of imagined offsetting or type 3 mitigation deterrence $\left(\mathrm{MD}_{3}\right.$ in the Supplementary material).

By contrast, with a counterfactual of a $1613 \mathrm{Gt}-\mathrm{C}$ RCP 8.5 emissions baseline (recalculated for 2020-2100) - still not entirely inconceivable given current political trends in countries such as the USA, Brazil, and Australia - the risk from imagined offsetting would reach 709823 Gt-C (see Supplementary Table 3). Once again, this calculation assumes that all expensive mitigation is at risk. In practice, one would expect some cultures, governments, and sectors to be more susceptible to the appeal of type 3 deterrence, and others less so. Therefore, the RCP8.5 counterfactual is excluded from the figures and not considered further.

\section{Summarizing the risks of mitigation deterrence}

This section brings together the preliminary estimates for the three types of mitigation deterrence considered in this paper. Table 1 summarizes the carbon at risk from all three 
mitigation deterrence types when set against a $1.5^{\circ} \mathrm{C}$ target, presenting a plausible 'worst-case' exceedance of the carbon budget for $1.5{ }^{\circ} \mathrm{C}$ by $371-545 \mathrm{Gt}-\mathrm{C}$. The range drops slightly to 371-513 Gt-C if using only the IPCC summary of GGR expectations, but would rise substantially if a counterfactual of RCP8.5 were used to estimate baseline emissions rather than RCP6.0. Higher figures would also be generated if the modelling synthesized here has underestimated direct land-use change implications of GGR, or if policy design generated a detectable Keynesian multiplier effect from GGR investment. In any case, it would appear that mitigation deterrence must be taken seriously and directly addressed by both researchers and policy makers concerned with GGR. Amongst other responses, it is hoped that modellers will seek to validate or improve these quantitative estimates of the scale of the risks and interrogate the assumptions presented regarding the inter-relations between the three types.

In terms of implications for temperatures, the exceedance of carbon budgets resulting from the substitution effects of GGR alone would be significant. Riahi et al. (2015) estimate a transient response of $0.6^{\circ} \mathrm{C}$, raising the average temperature outcome of RCP2.6 scenarios to $2.5^{\circ} \mathrm{C}$, rather than $1.9^{\circ} \mathrm{C}$; and Realmonte et al. (2019) suggest up to a $0.8^{\circ} \mathrm{C}$ overshoot if GGR were to fail to deliver as forecast after 2050. This analysis suggests that the overall effect of overoptimistic reliance on GGRs could be even more significant, for illustration, with unfavourable climate sensitivity, leading to an overshoot to $2.9^{\circ} \mathrm{C}$, despite policies aiming at $1.5^{\circ} \mathrm{C}$.

This estimate is based on the IPCC's transient sensitivity range of $0.73-2.57{ }^{\circ} \mathrm{C}$ per trillion tonnes of carbon (IPCC 2018). At the median value of $1.65^{\circ} \mathrm{C}$, the additional cumulative emissions shown in Table 1 equate to an additional $0.6-0.9^{\circ} \mathrm{C}$ of warming (Table 2). At the upper bound of $2.57^{\circ} \mathrm{C}$, they equate to $0.9-1.4^{\circ} \mathrm{C}$ extra warming. It should be noted that these figures relate only to the $\mathrm{CO}_{2}$ forcing. If the mechanisms here were to lead to additional emissions or rebounds of other greenhouse gases alongside $\mathrm{CO}_{2}$, the temperature effects would be proportionately higher. Matthews et al. (2018) report a lower observationally constrained range of $0.7-2.0{ }^{\circ} \mathrm{C}$ which would imply slightly lower figures.

A scenario in which all three forms of mitigation deterrence arise to the maximum extent estimated above may be unlikely, but still merits consideration. Complete failure may not be entirely implausible, given experience with fusion power, which is still typically promised 30 50 years into the future, after decades of research. Experience with nuclear fission and with CCS on fossil energy also suggests that significant underperformance is possible, and perhaps even predictable (Markusson et al. 2017). Even in the event of complete failure, GGRs could continue to stimulate reduced mitigation even while delivering zero withdrawals, because of the critical issue of timing. Delayed or reduced emissions cuts cannot be reversed at a future date if GGR fails then (in this respect the promises of GGR are more pernicious than the promises of fusion). If GGRs were to promise but never materialize (which makes types 1 and 3 deterrence significant), they would be unlikely to generate any type 2 effects (such as economic rebounds). Yet a worst case could arise if GGRs were to materialize but then

Table 2 Temperature implications of estimated carbon budget exceedances $\left({ }^{\circ} \mathrm{C}\right)$

Estimated exceedance

\begin{tabular}{llll}
\cline { 2 - 3 } TCRE (IPCC 2018) & Low (367 Gt-C) & Central (441 Gt-C) & High (544 Gt-C) \\
\hline 0.73 (low) & 0.27 & 0.32 & 0.40 \\
1.65 (median) & 0.60 & 0.73 & 0.90 \\
2.57 (high) & 0.94 & 1.13 & 1.40 \\
\hline
\end{tabular}


subsequently failed to deliver on their promises (type 1), in which case there may also be both type 2 and type 3 effects.

This analysis implies that the delivery of GGR requires policy and incentives which are robustly designed to avoid mitigation deterrence. It supports the view that GGR will be needed to offset some level of recalcitrant emissions, and most likely, to reverse a carbon budget overshoot. However, this analysis suggests that both such requirements might be 'reconstructed' in unhelpful ways - adjusting both their definition and scalein the light of promises of GGR. For example, in the presence of modelled GGR, the implied overshoot grows, as more expensive mitigation is postponed. In a similar way, GGR promises might enable continued use of otherwise stranded assets, or be mobilised to argue that expensive zero-carbon technologies for industrial processes or air-travel are (economically) impractical or unnecessary.

\section{Conclusions}

This paper has identified three types of potential mitigation deterrence: type 1 is direct substitution coupled with subsequent failure; type 2 involves additional emissions from rebounds, multipliers, and other indirect effects; and type 3 (the closest to a classic 'moral hazard' effect) is mitigation foregone through imaginary offsetting.

These effects could be additive, not just alternative ways in which emissions reductions might be delayed or deterred. Moreover, the problem is a matter for concern in part because of the temporal dimension-GGRs offer promises of 'future retrospective fixing' in which the GGR compensates for past emissions. By contrast, other future action taken in response to failures, limitations, or side-effects of GGR could not prevent or reverse emissions that had already happened because mitigation ambitions had not increased to the levels otherwise needed. The impacts of techno-fix promises of GGR may therefore be more pernicious than those of past climate techno-fixes such as nuclear power or fossil-CCS.

A plausible worst-case total level of cumulative 'carbon at risk' from the three types of mitigation deterrence has been calculated. Type 1 risks might constitute about $70 \%$ of promised removals, or 50-229 Gt-C. The type 2 risks quantified here account for an additional 25-134 Gt-C, and type 3 risk could reduce remaining emissions cuts 18-32\% (182-297 Gt-C). Added together, the cumulative carbon at risk to 2100 is $371-545 \mathrm{Gt}-\mathrm{C}$ (in the order of two to three times the amount of carbon removals promised).

The implications of this for global temperatures are that the committed temperature rise could be up to $1.4{ }^{\circ} \mathrm{C}$ higher than anticipated (in pathways otherwise expected to limit rises to $1.5^{\circ} \mathrm{C}$ ). This assumes all other impacts on climate forcings remain equal and that climate responses remain consistent even if emissions rates become net negative. Here, the nonclimate implications of different pathways have not been considered, but the replacement of mitigation with GGR might also have implications for inequality for example, depending on the nature of the techniques and the distribution of the increased residual emissions. More air travel, offset by BECCS based on annexation of cropland for bioenergy production, for example, could be expected to increase injustice in both respects.

These findings carry serious implications for research and policy. They do not, however, constitute an argument to halt or reduce research into GGR. This analysis rather confirms the great difficulty of meeting climate goals without deployment of GGR in some form(s). However, if the nature and scale of these risks is as portrayed here, it is incumbent upon both 
policy makers and researchers to consider and develop governance approaches for research and development which minimize the risks of deterrence. To facilitate this, will require greater disaggregation of the risks, and more detailed analysis of the potential political and psychosocial mechanisms by which they may emerge.

The analysis here has also implicated models and model makers in the generation of mitigation deterrence. Models (notably IAMs) have been, and are, a primary way in which expectations of climate action are shaped and consolidated, and this is especially true for imaginaries of GGR (Minx et al. 2017). Modellers tend to understand that models should be experimental sandpits, yet policy tends to treat them as truth machines (McLaren 2018). Developing responsible and deliberative ways to deploy and interpret models in politically charged climate debates where misinterpretation is rife, and multiple decision makers face conflicting incentives, is a key challenge for preventing mitigation deterrence. Consistently constraining models to avoid overshoots would be one helpful approach (Rogelj et al. 2019b). More generally, when developing governance of GGRs in the face of mitigation deterrence, interventions are needed that not only support the material delivery of functioning GGR but also minimize the offsets, substitution, and rebounds that constitute mitigation deterrence. Elsewhere, the present author has argued for a clear separation in target setting and incentives for emissions reduction and negative emissions, analogous to the 'Chinese walls' used in financial policy (McLaren et al. 2019). Measures that enhance the monitoring and verification of negative emissions would also help limit some forms of mitigation deterrence, as would measures which specifically incentivize or progressively mandate removal to storage, rather than just capture. Supporting portfolios of GGR rather than single technologies may also reduce risks and enable planning for some redundancy in delivery. Overall, and critically, there will remain a need for a reflexive framework that raises emissions reduction ambitions in advance of emerging deterrence effects.

Acknowledgments The author would like to thank his colleagues in the AMDEG project at Lancaster Environment Centre, especially Andrew Jarvis, for their constructive feedback on earlier drafts.

Funding information The manuscript was written with support from grant NE/P019838/1 from the programme Greenhouse Gas Removal from the Atmosphere, funded by NERC, EPSRC, ESRC, BEIS, Met Office \& STFC in the UK.

Data availability All data generated in this study is made available in the supplementary material.

Open Access This article is licensed under a Creative Commons Attribution 4.0 International License, which permits use, sharing, adaptation, distribution and reproduction in any medium or format, as long as you give appropriate credit to the original author(s) and the source, provide a link to the Creative Commons licence, and indicate if changes were made. The images or other third party material in this article are included in the article's Creative Commons licence, unless indicated otherwise in a credit line to the material. If material is not included in the article's Creative Commons licence and your intended use is not permitted by statutory regulation or exceeds the permitted use, you will need to obtain permission directly from the copyright holder. To view a copy of this licence, visit http://creativecommons.org/licenses/by/4.0/.

\section{References}

Allen MR, Frame DJ, Huntingford C, Jones CD, Lowe JA, Meinshausen M, Meinshausen N (2009) Warming caused by cumulative carbon emissions towards the trillionth tonne. Nature 458:1163

Alvarez RA, Zavala-Araiza D, Lyon DR, Allen DT, Barkley ZR, Brandt AR, Davis KJ, Herndon SC, Jacob DJ, Karion A, Kort EA, Lamb BK, Lauvaux T, Maasakkers JD, Marchese AJ, Omara M, Pacala SW, Peischl J, 
Robinson AL, Shepson PB, Sweeney C, Townsend-Small A, Wofsy SC, Hamburg SP (2018) Assessment of methane emissions from the U.S. oil and gas supply chain. Science 361(6398):186-188

Anderson K, Bows A (2008) Reframing the climate change challenge in light of post-2000 emission trends. Philos Trans R Soc A Math Phys Eng Sci 366(1882):3863

Anderson K, Peters G (2016) The trouble with negative emissions. Science 354(6309): 182

Armstrong K, Styring P (2015) Assessing the potential of utilization and storage strategies for post-combustion $\mathrm{CO} 2$ emissions reduction. Front Energy Res 3(8):1-9

Azar C, Johansson DJA, Mattsson N (2013) Meeting global temperature targets - the role of bioenergy with carbon capture and storage. Environ Res Lett 8(3):034004

Beck S, Mahony M (2018) The politics of anticipation: the IPCC and the negative emissions technologies experience. Global Sustainability 1:e8

Bednar J, Obersteiner M, Wagner F (2019) On the financial viability of negative emissions. Nat Commun 10(1): 1783

Bennett S, Stanley T. (2018) Commentary: US budget bill may help carbon capture get back on track, 12 March 2018. Retrieved 22/02/2019, from https:/www.iea.org/newsroom/news/2018/march/commentary-usbudget-bill-may-help-carbon-capture-get-back-on-track.html

Fuss S, Canadell JG, Peters GP, Tavoni M, others (2014) Betting on negative emissions. Nat Clim Chang 4:850853

Fuss S, Lamb WF, Callaghan MW, Hilaire J, Creutzig F, Amann T, Beringer T, de Oliveira Garcia W, Hartmann J, Khanna T, Luderer G, Nemet GF, Rogelj J, Smith P, Vicente JL, Wilcox J, del Mar Zamora Dominguez M, Minx JC (2018) Negative emissions_ part 2: costs, potentials and side effects. Environ Res Lett 13(6): 063002

Godec M, Kuuskraa V, Van Leeuwen T, Stephen Melzer L, Wildgust N (2011) CO2 storage in depleted oil fields: the worldwide potential for carbon dioxide enhanced oil recovery. Energy Procedia 4:2162-2169

Godec M, Carpenter S, Coddington K (2017) Evaluation of technology and policy issues associated with the storage of carbon dioxide via enhanced oil recovery in determining the potential for carbon negative oil. Energy Procedia 114:6563-6578

Goulder LH, Williams RC (2012) The choice of discount rate for climate change policy evaluation. Clim Chang Econ 03(04):1250024

Grubler A, Wilson C, Bento N, Boza-Kiss B, Krey V, McCollum DL, Rao ND, Riahi K, Rogelj J, De Stercke S, Cullen J, Frank S, Fricko O, Guo F, Gidden M, Havlík P, Huppmann D, Kiesewetter G, Rafaj P, Schoepp W, Valin H (2018) A low energy demand scenario for meeting the $1.5^{\circ} \mathrm{C}$ target and sustainable development goals without negative emission technologies. Nat Energy 3(6):515-527

IPCC (2007) Climate change 2007: mitigation. Contribution of working group III to the fourth assessment report of the intergovernmental panel on climate change. Cambridge University Press, Cambridge

IPCC (2018) Global warming of $1.5^{\circ} \mathrm{C}$. Switzerland, intergovernmental panel on climate change

Jouini E, Marin J-M, Napp C (2010) Discounting and divergence of opinion. J Econ Theory 145(2):830-859

Keith DW, Holmes G, St. Angelo D, Heidel K (2018) A process for capturing CO2 from the atmosphere. Joule

Larkin A, Kuriakose J, Sharmina M, Anderson K (2017) What if negative emission technologies fail at scale? Implications of the Paris Agreement for big emitting nations. Climate Policy

Luderer G, Vrontisi Z, Bertram C, Edelenbosch OY, Pietzcker RC, Rogelj J, De Boer HS, Drouet L, Emmerling J, Fricko O, Fujimori S, Havlík P, Iyer G, Keramidas K, Kitous A, Pehl M, Krey V, Riahi K, Saveyn B, Tavoni M, Van Vuuren DP, Kriegler E (2018) Residual fossil CO2 emissions in $1.5-2{ }^{\circ} \mathrm{C}$ pathways. Nat Clim Chang 8(7):626-633

Markusson N, Dahl Gjefsen M, Stephens JC, Tyfield D (2017) The political economy of technical fixes: the (mis)alignment of clean fossil and political regimes. Energy Res Soc Sci 23:1-10

Markusson N, McLaren D, Tyfield D (2018) Towards a cultural political economy of mitigation deterrence by negative emissions technologies (NETs). Global Sustainability 1:e10

Masnadi MS, Brandt AR (2017) Climate impacts of oil extraction increase significantly with oilfield age. Nat Clim Chang 7(8):551-556

Material Economics (2019) Industrial transformation 2050 - pathways to net-zero emissions from EU heavy industry. Cambridge, University of Cambridge Institute for Sustainability Leadership (CISL)

Matthews HD, Zickfeld K, Knutti R, Allen MR (2018) Focus on cumulative emissions, global carbon budgets and the implications for climate mitigation targets. Environ Res Lett 13(1):010201

McLaren D (2012) A comparative global assessment of potential negative emissions technologies. Process Saf Environ Prot 90(6):489-500

McLaren D (2016) Mitigation deterrence and the 'moral hazard' in solar radiation management. Earth's Future 4(12):596-602

McLaren DP (2018) Whose climate and whose ethics? Conceptions of justice in solar geoengineering modelling. Energy Res Soc Sci 44:209-221 
McLaren DP, Tyfield DP, Willis R, Szerszynski B, Markusson NO (2019) Beyond "net-zero": a case for separate targets for emissions reduction and negative emissions. Frontiers in Climate 1:4

Millar RJ, Fuglestvedt JS, Friedlingstein P, Rogelj J, Grubb MJ, Matthews HD, Skeie RB, Forster PM, Frame DJ, Allen MR (2017) Emission budgets and pathways consistent with limiting warming to $1.5^{\circ} \mathrm{C}$. Nat Geosci 10:741

Minx JC, Lamb WF, Callaghan MW, Bornmann L, Fuss S (2017) Fast growing research on negative emissions. Environ Res Lett 12(3):035007

Minx JC, Lamb WF, Callaghan MW, Fuss S, Hilaire J, Creutzig F, Amann T, Beringer T, de Oliveira Garcia W, Hartmann J, Khanna T, Lenzi D, Luderer G, Nemet GF, Rogelj J, Smith P, Vicente JL, Wilcox J, del Mar Zamora Dominguez M (2018) Negative emissions_-part 1: research landscape and synthesis. Environ Res Lett 13(6):063001

Oreskes N, Conway EM (2011) Merchants of doubt: how a handful of scientists obscured the truth on issues from tobacco smoke to global warming. Bloomsbury Press, London

Peters GP (2018) Beyond carbon budgets. Nat Geosci 11(6):378-380

Peters GP, Andrew RM, Solomon S, Friedlingstein P (2015) Measuring a fair and ambitious climate agreement using cumulative emissions. Environ Res Lett 10(10):105004

Realmonte G, Drouet L, Gambhir A, Glynn J, Hawkes A, Köberle AC, Tavoni M (2019) An inter-model assessment of the role of direct air capture in deep mitigation pathways. Nat Commun 10(1):3277

Riahi K, Kriegler E, Johnson N, Bertram C, den Elzen M, Eom J, Schaeffer M, Edmonds J, Isaac M, Krey V, Longden T, Luderer G, Méjean A, McCollum DL, Mima S, Turton H, van Vuuren DP, Wada K, Bosetti V, Capros P, Criqui P, Hamdi-Cherif M, Kainuma M, Edenhofer O (2015) Locked into Copenhagen pledges implications of short-term emission targets for the cost and feasibility of long-term climate goals. Technol Forecast Soc Chang 90:8-23

Rodriguez BS, Drummond P, Ekins P (2017) Decarbonizing the EU energy system by 2050: an important role for BECCS. Clim Policy 17(sup1):S93-S110

Rogelj J, Schaeffer M, Friedlingstein P, Gillett NP, van Vuuren DP, Riahi K, Allen M, Knutti R (2016) Differences between carbon budget estimates unravelled. Nat Clim Chang 6:245

Rogelj J, Popp A, Calvin KV, Luderer G, Emmerling J, Gernaat D, Fujimori S, Strefler J, Hasegawa T, Marangoni G, Krey V, Kriegler E, Riahi K, van Vuuren DP, Doelman J, Drouet L, Edmonds J, Fricko O, Harmsen M, Havlík P, Humpenöder F, Stehfest E, Tavoni M (2018) Scenarios towards limiting global mean temperature increase below $1.5^{\circ} \mathrm{C}$. Nat Clim Chang 8(4):325-332

Rogelj J, Forster PM, Kriegler E, Smith CJ, Séférian R (2019a) Estimating and tracking the remaining carbon budget for stringent climate targets. Nature 571(7765):335-342

Rogelj J, Huppmann D, Krey V, Riahi K, Clarke L, Gidden M, Nicholls Z, Meinshausen M (2019b) A new scenario logic for the Paris Agreement long-term temperature goal. Nature 573(7774):357-363

Rosen J (2018) The carbon harvest. Science 359(6377):733-737

Souza GM, Victoria RL, Joly CA, Verdade LM (2013) Bioenergy \& sustainability: bridging the gaps. Sao Paulo, SCOPE 72

van Vuuren DP, Stehfest E, Gernaat DEHJ, van den Berg M, Bijl DL, de Boer HS, Daioglou V, Doelman JC, Edelenbosch OY, Harmsen M, Hof AF, van Sluisveld MAE (2018) Alternative pathways to the $1.5^{\circ} \mathrm{C}$ target reduce the need for negative emission technologies. Nat Clim Chang 8(5):391-397

Vaughan NE, Gough C (2016) Expert assessment concludes negative emissions scenarios may not deliver. Environ Res Lett 11(9):095003

Wilcox J, Psarras PC, Liguori S (2017) Assessment of reasonable opportunities for direct air capture. Environ Res Lett 12(6):065001

Wiltshire A, Davies-Barnard T (2015) Planetary limits to BECCS negative emissions AVOID Working Paper

Publisher's note Springer Nature remains neutral with regard to jurisdictional claims in published maps and institutional affiliations. 